\title{
Therapeutic intervention scoring system-28 (TISS-28): diretrizes para aplicação
}

THERAPEUTIC INTERVENTION SCORING SYSTEM-28 (TISS-28): DIRECTIONS FORAPPLICATION

THERAPEUTIC INTERVENTION SCORING SYSTEM-28 (TISS-28): DIRECTRICES PARA SUAPLICACIÓN

Katia Grillo Padilha, Regina Marcia Cardoso de Sousa,Ana Maria Kazue Miyadahira, Diná de Almeida Lopes Monteiro da Cruz, Maria de Fátima Fernandes Vattimo, Miako Kimura, Sonia Aurora Alves Grossi, Maria Claudia Moreira da Silva, Valéria Ferraz Cruz, Adriana Janzanti Ducci ${ }^{1}$

\section{RESUMO}

O Therapeutic Intervention Scoring System-28 (TISS-28) é um instrumento que permite dimensionar carga de trabalho de enfermagem em Unidade de Terapia Intensiva e estimar gravidade da doença. Apresenta-se nesta publicação as definições operacionais para sua aplicação, proposta por um grupo de especialistas na área, com vistas a uniformizar o significado de cada um dos itens e evitar vieses de interpretação.

\section{DESCRITORES}

Cuidados intensivos.

Índice de gravidade de doença.

Carga de trabalho.

Enfermagem.

\section{ABSTRACT}

Therapeutic Intervention Scoring System-28 (TISS-28) is a tool that enables the measurement of the nursing work load in Intensive Care Units and the estimate of how grave the disease is. In this study are presented the operational definitions for its application, proposed by a group of specialists in the area, with the aim of rendering uniform the meaning of each of the items and preventing interpretation biases.

\section{KEY WORDS}

Intensive care.

Severity of illness index.

Workload.

Nursing.

\section{RESUMEN}

El Therapeutic Intervention Scoring System-28 (TISS-28) es un instrumento que permite dimensionar carga de trabajo de enfermería en una Unidad de Terapia Intensiva y estimar la gravedad de la enfermedad. Se presenta en esta publicación las definiciones operacionales para su aplicación, propuesta por un grupo de especialistas en el área, con vistas a uniformizar el significado de cada uno de los items y evitar sesgos de interpretación.

\section{DESCRIPTORES}

Cuidados intensivos. Indice de severidade de la enfermedad. Carga de trabajo. Enfermería.
1 Enfermeiros integrantes do grupo de Pesquisa em Enfermagem em UTI da EEUSP. Diretório dos Grupos de Pesquisa do CNPq.kgpadilh@usp.br 
Katia Grillo Padilha

Regina Marcia C. de Sousa

Ana Maria Kazue Miyadahira

Diná de A. L. M. da Cruz

Maria de Fátima F. Vattimo

Miako Kimura

Sonia Aurora Alves Grossi

Maria Claudia M. da Silva

Valéria Ferraz Cruz

Adriana Janzanti Ducci

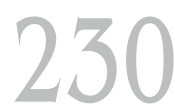

Rev Esc Enferm USP 2005; 39(2):229-33.

\section{INTRODUÇÃO}

O Therapeutic Intervention Scoring System (TISS) é um sistema de medida de gravidade e de carga de trabalho de enfermagem UTI, criado em 1974 e atualizado em 1983, que tem como base a quantificação das intervenções terapêuticas, segundo a complexidade, grau de invasividade e tempo dispensado pela enfermagem para a realização de determinados procedimentos no doente crítico ${ }^{(1-2)}$.

Com o intuito de tornar o índice mais ajustado para medir a carga de trabalho de enfermagem e facilitar a aplicação prática, ampla modificação foi realizada, em 1996, que resultou na versão TISS-28 (Anexo A) ${ }^{(3)}$.

Nessa nova estrutura o índice, além de sofrer redução do número de itens, teve mudanças expressivas na sua configuração, com o agrupamento de itens afins. O sistema passou a ser composto, então, por sete categorias de intervenções terapêuticas, assim denominadas: atividades básicas, suporte ventilatório, cardiovascular, renal, neurológico, metabólico e intervenções específicas. Com essa reestruturação, o escore TISS-28 permite não só estimar as intervenções e, portanto, a gravidade indireta dos pacientes, como também dimensionar a carga de trabalho de enfermagem na UTI, uma vez que cada ponto TISS-28 consome 10,6 minutos do tempo de trabalho de um profissional da equipe de enfermagem na assistência ao doente crítico ${ }^{(3)}$.

O sistema foi traduzido e validado para a língua portuguesa ${ }^{(4)}$, possibilitando a sua utilização no nosso meio. Na aplicação prática, porém, enfermeiros intensivistas têm referido dúvidas relacionadas à definição de alguns itens do instrumento, o que motivou a elaboração desse texto.

Assim, tendo por finalidade auxiliar os enfermeiros de UTI no preenchimento do TISS-28, à beira do leito, apresentam-se as definições operacionais padronizadas, por meio de consenso, por enfermeiros intensivistas e docentes do Grupo de Pesquisa Enfermagem em Cuidados Intensivos da Escola de Enfermagem da USP familiarizados com a sua aplicação. Acredita-se que esse guia possa contribuir para uma coleta de dados mais fidedigna, na medida em que permite a uniformização do conteúdo de cada item entre diferentes aplicadores.

\section{DEFINIÇÕES OPERACIONAIS}

\section{Atividades básicas}

1. Monitorização padrão. Sinais vitais horários, registros e cálculo regular do balanço hídrico.

Aplica-se ao paciente que, em qualquer período das 24 horas, tenha recebido controle de algum parâmetro vital continuamente ou pelo menos a cada uma hora e cálculo do balanço hídrico, pelo menos a cada 24 horas.

2. Laboratório. Investigações, bioquímicas e microbiológicas.

Aplica-se a pacientes submetidos a qualquer exame bioquímico ou microbiológico, independente da quantidade, realizados em laboratório ou à beira do leito.

\section{Mediação única. Endovenosa, intramuscular, subcutânea, elou oral.}

Inclui os pacientes que receberam uma ou mais droga por via IM, SC, VO ou uma única droga endovenosa. Considere a quantidade de drogas e não a freqüência de administração. Não se aplica como droga EV o soro de manutenção.

4. Medicações endovenosas múltiplas. Mais do que uma droga. Injeções únicas ou contínuas.

Inclui os pacientes que receberam duas ou mais drogas por via endovenosa. Considere a quantidade de drogas e não a freqüência de administração. Não se aplica como droga EV o soro de manutenção.

5. Troca de curativos de rotina. Cuidado e prevenção de úlceras de decúbito e troca diária de curativo.

Aplica-se ao paciente que recebeu uma ou duas sessões de troca de curativos, independente do número de locais e do tipo de curativo ou que recebeu qualquer intervenção de prevenção de úlcera de pressão.

6. Trocas freqüentes de curativos. Troca freqüente de curativo (pelo menos uma vez por turno de enfermagem) elou cuidados com feriadas extensas.

Aplica-se ao paciente que recebeu um mínimo de três sessões de troca de curativos, independente do numero de locais e do tipo de curativo ou pelo menos uma troca de curativo de ferida extensa.

7. Cuidados com drenos. Todos (exceto sonda nasogástrica) 
Aplica-se a pacientes que estejam com qualquer sistema de drenagem instalado. Inclui sonda vesical de demora (S.V.D). e exclui sonda nasogástrica (SNG).

\section{Suporte ventilatório}

8. Ventilação mecânica. Qualquer forma de ventilação mecânica/ventilação assistida com ou sem pressão expiratória positiva final, com ou sem relaxantes musculares; respiração espontânea com pressão expiratória positiva final.

Aplica-se ao paciente em uso do aparelho de ventilação mecânica de modo contínuo ou intermitente, em qualquer modalidade, com ou sem tubo endotraqueal (CPAP, BPAP "Desmame").

9. Suporte ventilatório suplementar. Respiração espontânea através do tubo endo traqueal sem pressão expiratória positiva final; oxigênio suplementar por qualquer método, exceto aplicação de parâmetros de ventilação mecânica.

Aplica-se ao paciente em respiração espontânea, com ou sem traqueotomia ou tubo endotraqueal, que tenha recebido suplementação de oxigênio por qualquer método, executando-se aqueles métodos que dependem de aparelho de ventilação. Nestes casos o paciente pontua no item anterior.

10. Cuidados com vias aéreas artificiais. Tubo endotraqueal ou traqueotomia.

Aplica-se ao paciente em uso de tubo orotraqueal, nasotraqueal ou traqueotomia.

11. Tratamento para melhora da função pulmonar. Fisioterapia, torácica, espirometria estimulada, terapia de inalação, aspiração endotraqueal.

Aplica-se ao paciente que tenha recebido qualquer tratamento para a melhora da função pulmonar, realizado em qualquer freqüência. Inclui exercícios respiratórios com aparelho.

\section{Suporte cardiovascular}

12. Medicação vasoativa única. Qualquer droga vasoativa.

Aplica-se ao paciente que tenha recebido somente uma droga vasoativa, independente do tipo de dose (noradrenalina, dopamina, dobutamina, nitroprussiato de sódio, etc.)

13. Medicação vasoativa múltipla. Mais uma droga vasoativa, independente do tipo e dose.
Aplica-se ao paciente que tenha recebido duas ou mais drogas vasoativas, independente do tipo e da dose ( noradrenalina, dopamina, dobutamina, nitroprussiato de sódio, etc.)

14. Reposição endovenosa de grandes perdas volêmicas. Administração de volume $>4,5$ litros/ dia, independente do tipo de fluido administrado.

Aplica-se a paciente que tenha recebido quantidade maior do que 4,5 litros de solução por dia, independente do tipo de fluido administrado.

\section{Cateter arterial periférico.}

Aplica-se ao paciente que tenha usado um ou mais cateteres em artéria periférica.

16. Monitorização do átrio esquerdo. Cateter de artéria pulmonar com ou sem medida de débito cardíaco.

Aplica-se ao paciente que tenha usado cateter em artéria pulmonar.

\section{Via venosa central.}

Aplica-se ao paciente com um ou mais cateteres em veia venosa central, excluindo cateter de Swan-Ganz.

18. Ressuscitação cardiopulmonar, após parada cardiorrespiratória nas últimas vinte e quatro (24) horas (exclui soco precordial).

Aplica-se ao paciente que tenha tido PCR e recebido medidas de reanimação, excluindo soco precordial.

\section{Suporte renal}

19. Técnicas de hemofiltração. Técnicas dialíticas.

Aplica-se ao paciente que tenha recebido qualquer tipo de procedimento dialítico, intermitente ou contínuo.

\section{Medida quantitativa do débito urinário}

Aplica-se ao doente com controle de diurese, com ou sem algum tipo de cateter urinário.

\section{Diurese ativa.}

Aplica-se ao paciente que tenha recebido qualquer droga para estimular a produção de urina (Furosemide, Manitol, Aldactone, Diamox, Higroton, etc.)

\section{Suporte neurológico}

\section{Medida de pressão intracraniana.}

Aplica-se ao paciente que mantém artefatos para monitorização da PIC.
Therapeutic

intervention scoring

system-28 (TISS-28):

Diretrizes para

aplicação 
Katia Grillo Padilha

Regina Marcia C. de Sousa Ana Maria Kazue Miyadahira

Diná de A. L. M. da Cruz

Maria de Fátima F. Vattimo

Miako Kimura

Sonia Aurora Alves Grossi

Maria Claudia M. da Silva

Valéria Ferraz Cruz

Adriana Janzanti Ducci

\section{Suporte metabólico}

23. Tratamento medicamentoso da acidose/ alcalose metabólica complicada.

Aplica-se ao paciente que recebeu droga específica para a correção de acidose ou alcalose metabólica, excluindo-se a reposição volêmica para corrigir alcalose (Bicarbonato de Sódio, Cloreto de amônia, Diamox, etc.).

\section{NPT-Nutrição Parenteral Total.}

Aplica-se ao paciente que recebeu infusão venosa central ou periférica de substâncias com a finalidade de suprir as necessidades nutricionais.

25. Nutrição enteral através da sonda nasogástrica ou outra via gastrointestinal.

Aplica-se ao paciente que recebeu substâncias com a finalidade de suprir as necessidades nutricionais, através de sonda, por qualquer via do trato gastrointestinal.

\section{Intervenções específicas}

26. Intervenção especifica única na UTI. Intubação naso / ortotraqueal ou traqueostomia, introdução de marca-passo, cardioversão, endoscopia, cirurgia de emergência nas ultimas 24 horas, lavagem gástrica: não estão incluídas intervenções de rotina sem conseqüências diretas para as condições clínicas do paciente, tais como radiografias, icnografias, eletrocardiograma, curativos, introdução de cateter venoso ou arterial.

Aplica-se ao paciente submetido a uma única intervenção diagnóstica ou terapêutica, dentre as listadas, realizada dentro da UTI.

27. Intervenções especificas múltiplas na UTI. Mais do que uma conforme descritas acima.

Aplica-se ao paciente submetido a duas ou mais intervenções diagnósticas ou terapêuticas, dentre as listadas, realizadas dentro da UTI.

28. Intervenções especificas fora da UTI. Procedimentos diagnósticos ou cirúrgicos.

\section{REFERÊNCIAS}

(1) Cullen DJ. Therapeutic intervention scoring system: a method for quantitative comparison of patient care. Crit Care Med 1974; 2 (2): 57-60.

(2) Keene AR, Cullen DJ. Therapeutic intervention scoring system: update 1983. Crit Care Med 1983; 11(1): 1-3.
Aplica-se ao paciente submetido a uma ou mais intervenções diagnósticas ou terapêuticas realizadas fora da UTI.

Obs: Critérios de exclusão são aplicadas em quatro condições: "medicação endovenosa múltipla" exclui "medicação única", "ventilação mecânica" exclui "suporte ventilatório suplementar", "medicação vaso ativa múltipla" exclui "medicação vasoativa única", "intervenções específicas múltiplas na UTI" excluem "intervenções especificas únicas na UTI".

\section{CONSIDERAÇÕES FINAIS}

A definição operacional dos itens de qualquer instrumento de medida constitui elemento essencial para o sucesso dos resultados que se pretende alcançar, o que também se aplica para o TISS-28.

Porém, a despeito da importância dessas definições operacionais, sua existência, por si só, não é suficiente para garantir uma coleta de dados que resulte em informações corretas e fidedignas.

No caso do TISS-28, para que isso ocorra, antecedendo a aplicação propriamente dita, é indispensável que os enfermeiros envolvidos na coleta de dados conheçam as finalidades do índice, sua indicação, contribuições e limitações, o que exige treinamento prévio e sistematizado, inclusive, com teste piloto voltado à "calibragem" dos profissionais que aplicarão o instrumento. Também é fundamental que se atente para os itens excludentes, a fim de que não haja atribuição errônea de pontuação.

Enfim, embora o sucesso da aplicação do TISS-28 dependa da sua disponibilidade na unidade, da existência de instruções escritas para utilização e do treinamento dos aplicadores, a motivação e envolvimento dos enfermeiros da UTI é que garantirão o sucesso da implantação do instrumento, uma vez que, certamente, serão solicitados a complementar informações, nem sempre disponíveis nos registros existentes.

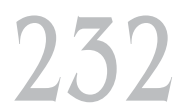

Rev Esc Enferm USP 2005; 39(2):229-33
(3) Miranda DR, Rijk AD, Schaufeli W. Simplified therapeutic intervention scoring system: the TISS28 itens-results from a multicenter study. Crit Care Med 1996; 24 (1): 64-73.

(4) Nunes B. Tradução para o português e validação de um instrumento de medida de gravidade em UTI: Therapeutic Intervention Scoring System-28 (TISS-28) [dissertação] São Paulo (SP): Escola de Enfermagem da USP; 2000. 
ANEXO

TISS - 28

\section{Atividades Básicas}

Monitorização padrão. Sinais Vitais horários, registros e cálculo regular do balanço hídrico

Laboratório. Investigações bioquímicas e microbiológicas

Medicação única. Endovenosa, intramuscular, subcutânea, e/ou oral / SNG

Medicações endovenosas múltiplas. Mais que uma droga.

Troca de curativos de rotina. Cuidado e prevenção de úlceras de decúbito / troca diária de curativo

Trocas freqüentes de curativos. Troca freqüente de curativo (pelo menos uma vez por turno de enfermagem) e/ou cuidados com feridas extensas

Cuidados com drenos. Todos (exceto SNG)

\begin{tabular}{|l|l|}
\hline 5 & \\
\hline 1 & \\
\hline 2 & \\
\hline 3 & \\
\hline 1 & \\
\hline 1 & \\
\hline 3 & \\
\hline
\end{tabular}

Suporte Ventilatório

Ventilação mecânica. Qualquer forma de ventilação mecânica/ventilação assistida com ou sem PEEP. Com ou sem relaxantes musculares respiração espontânea com PEEP

Suporte ventilatório suplementar. Respiração espontânea através do tubo endotraqueal sem PEEP; O2 suplementar por qualquer método exceto aplicação de parâmetros de ventilação mecânica

Cuidados com vias aéreas artificiais. Tubo endotraqueal ou traqueostomia

Tratamento par melhora da função pulmonar. Fisioterapia torácica, espirometria estimulada,

terapia de inalação, aspiração endotraqueal

Suporte Cardiovascular

Medicação vasoativa única. Qualquer droga vasoativa

Medicação vasoativa múltipla. Mais que uma droga vasoativa independente do tipo e dose

Reposição de grandes perdas volêmicas. Administração de volume $>31 / \mathrm{m}^{2} / \mathrm{d}$, independente do tipo.

Cateter arterial periférico.

Monitorização do átrio esquerdo. Cateter de artéria pulmonar com ou sem medida de débito cardíaco.

Via venosa central.

Ressuscitação cardiopulmonar ( PCR nas últimas 24 horas ).

\begin{tabular}{|l|l|}
\hline 5 & \\
\hline 2 & \\
\hline 1 & \\
\hline 1 & \\
\hline
\end{tabular}

\section{Suporte Renal}

Técnicas de hemofiltração. Técnicas dialíticas.

Medida quantitativa do débito urinário (ex : SVD ).

Diurese ativa ( ex : furosemida $>0,5 \mathrm{mg} / \mathrm{Kg} /$ dia )

\begin{tabular}{|l|l|}
\hline 3 & \\
\hline 4 & \\
\hline 4 & \\
\hline 5 & \\
\hline 8 & \\
\hline 2 & \\
\hline 3 & \\
\hline
\end{tabular}

SuporteNeurológico

Medida de Pressão Intracraniana.

Suporte Metabólico

Tratamento de acidose/alcalose metabólica complicada

Nutrição Parenteral Total endovenosa.

Nutrição enteral (ex. SNG) ou outra via como por ex: jejunostomia.

\begin{tabular}{|l|l|}
\hline 3 & \\
\hline 2 & \\
\hline 3 &
\end{tabular}

Intervenções específicas

Intervenção específica única na UTI. Intubação naso ou orotraqueal, introdução de marcapasso, cardioversão, endoscopia, cirurgia de emergência nas últimas $24 \mathrm{~h}$, lavagem gástrica, não estão incluídas intervenções de rotina sem conseqüências diretas para as condições do paciente, tais como RX, ecografias, ECG, curativos, introdução de cateter venoso central.

Intervenções específicas múltiplas na UTI. Mais que uma conforme descritas acima. Intervenções específicas fora da UTI. Procedimentos diagnósticos ou cirúrgicos. 